\title{
Role of the 26-Hydroxylase in the Biosynthesis of Bile Acids in the Normal State and in Cerebrotendinous Xanthomatosis
}

\author{
AN IN VIVO STUDY
}

\author{
Ingemar Björkhem, Olav Fausa, Gunnar Hopen, Helge Oftebro, \\ Jan I. Pedersen, and Sverre Skrede, Department of Clinical Chemistry and \\ Research Centre at Huddinge University Hospital, Karolinska Institutet, \\ Stockholm, Sweden; Medical Department A and Institute of Clinical \\ Biochemistry, Rikshospitalet, University of Oslo, Medical Department B, \\ Haukeland Hospital, University of Bergen, Institute for Nutrition Research, \\ School of Medicine, University of Oslo, Norway
}

\begin{abstract}
A в S T R A CT On the basis of different in vitro studies, we have previously suggested that the basic metabolic defect in the rare inherited disease cerebrotendinous xanthomatosis (CTX) is a lack of a hepatic mitochondrial $\mathrm{C}_{27}$-steroid 26-hydroxylase, involved in the normal biosynthesis of bile acids (1980. J. Clin. Invest. 65: 1418-1430; 1981. J. Lipid Res. 22: 191-200; 22: 632-640).

In the present work, this hypothesis was tested in vivo. One patient with CTX and two control subjects received intravenously a mixture of $\left[4-{ }^{14} \mathrm{C}\right] 7 \alpha$-hydroxy-4-cholesten-3-one and $\left[6 \beta-{ }^{3} \mathrm{H}\right] 7 \alpha, 26$-dihydroxy4-cholesten-3-one, steroids believed to be important precursors of chenodeoxycholic acid. The ratio between ${ }^{14} \mathrm{C}$ and ${ }^{3} \mathrm{H}$ in cholic acid and chenodeoxycholic acid isolated from bile of the CTX-patient was $\sim 1 /$ 40 and $1 / 60$ of those of the control subjects, respectively. Another patient with CTX and one control subject received a mixture of $\left[4-{ }^{14} \mathrm{C}\right] 5 \beta$-cholestane- $3 \alpha, 7 \alpha$ diol and $\left[1,2-{ }^{3} \mathrm{H}\right] 5 \beta$-cholestane- $3 \alpha, 7 \alpha, 26$-triol, both possible precursors to chenodeoxycholic acid. In this case the ${ }^{14} \mathrm{C} /{ }^{3} \mathrm{H}$ ratio in cholic acid and chenodeoxycholic acid from the patient with CTX was $1 / 10$ and $1 / 15$, respectively, compared with that of the control subject.

The most likely explanation for these findings is that
\end{abstract}

\footnotetext{
Address reprint requests to Dr. Björkhem, Huddinge University Hospital.

Received for publication 14 December 1981 and in revised form 9 September 1982.
}

very little of the ${ }^{14} \mathrm{C}$-precursors, i.e. without a 26 -hydroxyl group, can be converted into cholic acid and chenodeoxycholic acid because of a defect of the 26hydroxylase step.

The results obtained are in accord with our previous findings in vitro. The results further underline the importance of the 26-hydroxylase pathway in the normal biosynthesis of cholic acid and chenodeoxycholic acid in man.

\section{INTRODUCTION}

According to the most common concept, the degradation of the cholesterol side chain in the biosynthesis of bile acids starts with a mitochondrial 26-hydroxylation followed by an oxidation to give a carboxylic acid $(1,2)$. After further oxidation by introduction of a hydroxyl group in 24-position, propionic acid is cleaved off and the bile acid is obtained. In the biosynthesis of chenodeoxycholic acid, the most likely substrates for the 26 -hydroxylase seem to be $5 \beta$-cholestane- $3 \alpha, 7 \alpha$,diol and $7 \alpha$-hydroxy-4-cholesten-3-one, whereas $5 \beta$-cholestane- $3 \alpha, 7 \alpha, 12 \alpha$-triol and $7 \alpha, 12 \alpha$-dihydroxy-4-cholesten-3-one are likely substrates in the biosynthesis of cholic acid (1-6). In a recent work (7), we showed that the liver of a patient with the rare inherited metabolic disease cerebrotendinous xanthomatosis $(\mathrm{CTX})^{1}$ was completely devoid of mito-

\footnotetext{
${ }^{1}$ Abbreviations used in this paper: CTX, cerebrotendinous xanthomatosis; GC-MS, gas chromatography-mass spectrometry; HPLC, high-performance liquid chromatography.
} 
chondrial 26-hydroxylase activity. In the liver of this patient there was a considerable accumulation of the above steroids, believed to be major substrates for the mitochondrial 26-hydroxylase (6). ${ }^{2}$

In addition a pathway has been described involving a microsomal 25 -hydroxylation followed by a $24 \beta$-hydroxylation $(8,9)$. Further oxidation of the $24 \beta-, 25$ dihydroxylated side chain yields acetone and a bile acid. The microsomal 25-hydroxylase has a high specificity towards $5 \beta$-cholestane- $3 \alpha, 7 \alpha, 12 \alpha$-triol (3), and consequently cholic acid is the major product of this pathway.

The relative importance of the two pathways is controversial. Patients with CTX are known to excrete considerable amounts of $5 \beta$-cholestane- $3 \alpha, 7 \alpha-12 \alpha, 25$ tetrol and $5 \beta$-cholestane- $3 \alpha, 7 \alpha, 12 \alpha, 24,25$-pentol in bile and feces $(10)$. We have suggested that this excretion is due to the lack of the mitochondrial 26-hydroxylase required for normal bile acid biosynthesis. Accumulation of $5 \beta$-cholestane- $3 \alpha, 7 \alpha, 12 \alpha$-triol might lead to an exposure of this steroid to the otherwise less active microsomal 25-hydroxylase.

In contrast, Salen et al. have discussed the possibility that the 25-hydroxylase pathway may be the major pathway in the formation of cholic acid in human liver $(8,9)$. If so, the basic metabolic defect in CTX is a reduced capacity to convert $5 \beta$-cholestane$3 \alpha, 7 \alpha, 12 \alpha, 25$-tetrol into cholic acid. The authors found a delayed conversion of labeled $5 \beta$-cholestane$3 \alpha, 7 \alpha, 12 \alpha, 25$-tetrol into cholic acid in vivo $(8,9)$ and a relatively low $24 \beta$-hydroxylase activity in vitro (reduced to one-fourth) in patients with CTX as compared to control subjects (11). Also the conversion of labeled $5 \beta$-cholestane- $3 \alpha, 7 \alpha, 26$-triol and $7 \alpha$-hydroxy4-cholesten-3-one into cholic acid and chenodeoxycholic acid in vivo appeared to be impaired in patients with CTX (12).

The reduced conversion of $5 \beta$-cholestane- $3 \alpha$,$7 \alpha, 12 \alpha, 25$-tetrol in vivo and in vitro in patients with CTX may be explained by an expanded endogenous pool of steroids, which might dilute and compete with the exogenous labeled steroid administered (cf. ref. 6, 7). The delayed conversion of $5 \beta$-cholestane- $3 \alpha, 7 \alpha, 26$ triol into bile acids found by Salen et al. is unexpected. The large amounts of accumulated bile alcohols may give secondary effects on the liver and obvious signs

\footnotetext{
2 26-Hydroxylation: This hydroxylation may be a 26 -hydroxylation or a 27-hydroxylation (hydroxylation of the 25pro- $R$-methyl group or the 25-pro- $S$-methyl group, respectively). For a more detailed discussion, see the footnote in ref. 7 . Because the stereospecificity might be different in different species and with different substrates, we prefer here to denote the $\omega$-hydroxylation of the side-chain of the $\mathrm{C}_{27}$-steroids as 26 -hydroxylation.
}

of liver damage were present in the two patients with CTX whom we have studied.

In the present work we have synthesized $4-{ }^{14} \mathrm{C}$-labeled $5 \beta$-cholestane- $3 \alpha, 7 \alpha$-diol and $7 \alpha$-hydroxy-4cholesten-3-one as well as ${ }^{3} \mathrm{H}$-labeled $5 \beta$-cholestane$3 \alpha, 7 \alpha, 26$-triol and $7 \alpha, 26$-dihydroxy-4-cholesten-3-one. $5 \beta$-Cholestane- $3 \alpha, 7 \alpha$-diol or $7 \alpha$-hydroxy-4-cholesten3 -one were then administered simultaneously with the corresponding 26-hydroxylated steroid both to CTXpatients and to control subjects. The relative conversion into cholic acid and chenodeoxycholic acid was evaluated by measuring the ratio between ${ }^{14} \mathrm{C}$ and ${ }^{3} \mathrm{H}$ in cholic acid and chenodeoxycholic acid isolated from bile. With such an experimental approach, it should be possible to evaluate the importance of introduction of a 26-hydroxyl group in the biosynthesis of bile acids and to obtain valid information even if there is a generally reduced capacity to convert different $\mathrm{C}_{27}$-steroids into bile acids due to impaired liver function.

\section{METHODS}

\section{Materials}

Clinical. Two sisters, I.J. (born 6 May 1935) and A.F. (born 27 July 1941) with CTX were studied. Detailed records have been published previously (7). By neurological examination during this stay, I.J. was found to be mentally retarded and to have definite neurological dysfunction including ataxia. She was moderately disabled, also because of extensive xanthomatosis. Cerebral computer tomography showed central and cortical atrophy of moderate severity. Laboratory values (normal reference ranges are indicated in a parenthesis): serum total cholesterol $7.2 \mathrm{mmol} /$ liter (3.57.5), triglycerides $2.8 \mathrm{mmol} /$ liter (0.6-1.4), ASAT $25 \mathrm{U} /$ liter (13-38), ALAT 16 U/liter (9-29), alkaline phosphatases 168 U/liter (55-195), and GT 29 U/liter (6-26). A.F. was slightly mentally retarded and less disabled than I.J. She had xanthomatosis, but less extensive than the elder sister. Cerebral computer topography was normal. Laboratory data: serum total cholesterol $8.5 \mathrm{mmol} /$ liter, triglycerides $1.1 \mathrm{mmol} /$ liter, ASAT $42 \mathrm{U} /$ liter, ALAT $58 \mathrm{U} /$ liter, alkaline phosphatases $265 \mathrm{U} /$ liter and GT $30 \mathrm{U} /$ liter.

Needle liver biopsies were obtained from both CTX-patients. In I.J., light microscopy showed slight liver steatosis, and electron microscopy also crystalloid inclusions in the mitochondria. In A.F. severe steatosis and collagenization of Disse's space were observed. Electron microscopy showed similar inclusions as were found in mitochondria from I.J.

Control patient I was G.H. (female, born 12 May 1925). She underwent examinations for a pancreatic tumor that was removed and classified as a malignant "APUD-oma" (APUD, amine precursor uptake and decarboxylation). Control patient III, P.L.I. (male, born 18 December 1950) suffered from irritable colon. Control patient II L.A. (female, born 25 September 1925) suffered from diabetes mellitus and polyneuropathia of unknown cause. No signs of intestinal or liver disease were found in any of these patients and there were normal values for serum total cholesterol, serum triglycerides, alkaline phosphatases, ASAT, ALAT, and total bilirubin.

The ethical aspects of the present study was approved by the ethical board of the Norwegian Council for Science and 
the Humanities, Division for Medical Research. Informed consent was obtained from all patients and in addition from the family of the two CTX-patients.

Preparation of labeled steroids. $\quad 4-{ }^{14} \mathrm{C}$-labeled $7 \alpha$-hydroxy-4-cholesten-3-one was prepared from $4-{ }^{14} \mathrm{C}$ labeled cholesterol (obtained from Radiochemical Centre, Amersham, England) according to a previously described procedure (16). The material was purified by high-performance liquid chromatography (HPLC). The material obtained was pure as shown by thin-layer chromatography, using benzeneethyl acetate $(1: 1, \mathrm{vol} / \mathrm{vol})$ as solvent and by gas-liquid chromatography on SE-30 column (as trimethylsilyl ether). The specific radioactivity was $4.2 \times 10^{6} \mathrm{dpm} / \mathrm{mg}$.

$4-{ }^{14} \mathrm{C}$-Labeled $5 \beta$-cholestane- $3 \alpha, 7 \alpha$-diol was prepared biosynthetically from the above $\left[4-{ }^{14} \mathrm{C}\right] 7 \alpha$-hydroxy-4-cholesten3 -one by incubation with the cytosolic fraction of a rat liver homogenate under the conditions previously described (17). The degree of conversion varied between 30 and $50 \%$ in the various incubations. The product was purified by preparative thin-layer chromatography, using the same conditions as above and by HPLC (15). The material was pure when tested by thin-layer chromatography and gas-liquid chromatography, using the same conditions as above. The specific radioactivity was $4.2 \times 10^{6} \mathrm{dpm} / \mathrm{mg}$.

$1,2-{ }^{3} \mathrm{H}$-Labeled $5 \beta$-cholestane- $3 \alpha, 7 \alpha, 26$-triol and $6 \beta-{ }^{3} \mathrm{H}$ labeled $7 \alpha$-26-dihydroxy-4-cholesten-3-one were prepared from $\left[1,2-{ }^{3} \mathrm{H}\right] 5 \beta$-cholestane- $3 \alpha, 7 \alpha$-diol and $\left[6 \beta-{ }^{3} \mathrm{H}\right] 7 \alpha$-hydroxy-4-cholesten-3-one, respectively, by incubation with a reconstituted system of cytochrome P-450 from human liver mitochondria followed by purification on HPLC (15). [6 $\beta$ $\left.{ }^{3} \mathrm{H}\right] 7 \alpha$-Hydroxy-4-cholesten-3-one was prepared by the same route as that described for synthesis of $\left[4-{ }^{14} \mathrm{C}\right] 7 \alpha$-hydroxy-4cholesten-3-one, with the exception that unlabeled cholesterol and ${ }^{3} \mathrm{H}$-labeled lithium aluminium hydride (obtained from New England Nuclear, Boston, MA) were used in the procedure (18). In the biosynthesis of $\left[1,2-{ }^{3} \mathrm{H}\right] 5 \beta$-cholestane$3 \alpha, 7 \alpha$-diol, $\left[1,2-{ }^{3} \mathrm{H}\right] 7 \alpha$-hydroxy-4-cholesten-3-one was prepared as above with use of $\left[1,2-{ }^{3} \mathrm{H}\right]$ cholesterol as starting material (obtained from Radiochemical Centre) followed by incubation with rat liver cytosol as above. Both compounds were purified by HPLC (15) before incubation.

The identification of the final products as $5 \beta$-cholestane$3 \alpha, 7 \alpha, 26$-triol and $7 \alpha, 26$-dihydroxy-4-cholesten-3-one was performed by analyzing their trimethylsilyl ethers (20) on gas liquid chromatography - mass spectrometry (GLC-MS), using a $1.5 \% \mathrm{SE}$ column at $280^{\circ} \mathrm{C}$ and an $\mathrm{LKB} 9000$ instrument (LKB Instruments Inc., Stockholm, Sweden), equipped with a multiple ion detector. A compound was regarded as identical with a certain authentic standard when the two compounds cochromatographed on HPLC and GLC and contained one or several characteristic ions in common in their mass spectra. This method has been described in detail previously $(6,15,21)$. Both compounds were found to be pure and have a specific radioactivity of $42 \times 10^{6} \mathrm{dpm} / \mathrm{mg}$.

All chemicals and solvents used in the present study were standard commercial high purity materials.

\section{Procedures}

Administration of labeled steroids and collection of bile. CTX patients A.F., and control subject G.H. received by intravenous infusion simultaneously $\left[4-{ }^{14} \mathrm{C}\right] 5 \beta$-cholestane$3 \alpha, 7 \alpha$-diol and $\left[1,2-{ }^{3} \mathrm{H}\right] 5 \beta$-cholestane- $3 \alpha, 7 \alpha, 26$-triol, and her sister I.J., control subject II, L.A., and III, P.L.I. $\left[4{ }^{14}{ }^{14}\right] 7 \alpha-$ hydroxy-4-cholesten-3-one and $\left[6 \beta-{ }^{3} \mathrm{H}\right] 7 \alpha, 26$-dihydroxy-4cholesten-3-one. Fixed amounts (Table I) of the radioactive labeled steroids were dissolved in $0.5 \mathrm{ml}$ of ethanol, and slowly added under shaking to $30 \mathrm{ml}$ of a sterile human albumin solution (albumin 20\%, Kabi AB, Stockholm, Sweden). The solution was passed through a Millex $0.22-\mu \mathrm{m}$

TABIE: I

Percentage of ${ }^{3} \mathrm{H}$-Activity in Ether Extract Recovered in Bile Acids, and ${ }^{14} \mathrm{C}_{/}^{3} \mathrm{H}$ Ratios in Bile Acids Isolated from the Control Subjects and the CTX Patients

\begin{tabular}{|c|c|c|c|c|}
\hline & \multicolumn{2}{|c|}{$\begin{array}{l}\text { Percentage of }{ }^{3} \mathrm{H} \text {-actwity } \\
\text { in ether extract recovered in }\end{array}$} & \multicolumn{2}{|c|}{${ }^{14} \mathrm{C} /{ }^{3} \mathrm{H} \mathrm{l}$ in } \\
\hline & $\begin{array}{l}\text { Cholic } \\
\text { acid }\end{array}$ & $\begin{array}{l}\text { Chenodeorycholic } \\
\text { acid }\end{array}$ & $\begin{array}{l}\text { Cholic } \\
\text { acid }\end{array}$ & $\begin{array}{l}\text { Chenexdeoxycholic } \\
\text { acid }\end{array}$ \\
\hline & $\because$ & ci & & \\
\hline \multicolumn{5}{|c|}{$\begin{array}{l}\text { Bile from control subjects given }\left[6 \beta-{ }^{3} \mathrm{H}\right] 7 \alpha, 26 \text {-dihydroxy-4-cholesten-3-one } \\
+\left[4-{ }^{-14} \mathrm{C}\right] 7 \alpha \text {-hydroxy-4-cholesten-3-one }\end{array}$} \\
\hline Control II & 6.7 & 23 & 1.53 & 0.38 \\
\hline Control III & 11 & 33 & 1.38 & 0.39 \\
\hline \multicolumn{5}{|c|}{ Bile from CTX-patient (I.J.) given $\left[6 \beta-{ }^{3} \mathrm{H}\right] 7 \alpha, 26$-dihydroxy-4-cholesten-3-one } \\
\hline$+\left[4-{ }^{14} \mathrm{C}\right] 7 \alpha$-hydroxy-4-cholesten-3-one & 2.3 & 43.3 & 0.032 & 0.004 \\
\hline \multicolumn{5}{|c|}{ Bile from control subject I given $\left[1,2-{ }^{3} \mathrm{H}\right] 5 \beta$-cholestane- $3 \alpha, 7 \alpha, 26$-triol } \\
\hline$+\left[4-{ }^{14} \mathrm{C}\right] 5 \beta$-cholestane- $3 \alpha, 7 \alpha$-diol ${ }^{\bullet}$ & 55 & 34 & 0.69 & 0.10 \\
\hline \multicolumn{5}{|c|}{ Bile from CTX-patient (A.F.) given $\left[1,2-{ }^{3} \mathrm{H}\right] 5 \beta$-cholestane- $3 \alpha-7 \alpha, 26$-triol } \\
\hline$+\left[4-{ }^{14} \mathrm{C}\right] 5 \beta$-cholestane- $3 \alpha, 7 \alpha$-diol & 12 & 51 & 0.06 & 0.004 \\
\hline
\end{tabular}

- The ${ }^{14} \mathrm{C} /{ }^{3} \mathrm{H}$ in this material was 0.80 . The total disintegrations per minute given was $3.06 \times 10^{6}$ with respect to 3 and $2.47 \times 10^{6}$ with respect to ${ }^{14} \mathrm{C}$.

I The ${ }^{14} \mathrm{C} /{ }^{3} \mathrm{H}$ in this material was 0.22 . The total disintegrations per minute given was $1.45 \times 10^{6}$ with respect to ${ }^{3} \mathrm{H}$ and $0.32 \times 10^{65}$ with respect to ${ }^{14} \mathrm{C}$. 
filter (Millipore Corp., Bedford, MA). A fat- and proteinrich meal (to promote gallbladder emptying) was given 17 $h$ before the duodenal intubation, and the infusion of precursors was performed (in less than $30 \mathrm{~min}$ ) $3 \mathrm{~h}$ after the meal. After the infusion, the patients fasted until after sampling of duodenal contents. Duodenal intubation was performed with a Lagerlöf double-lumen tube under fluoroscopic control. Contamination by gastric contents was avoided by separate aspiration. Duodenal contents were collected quantitatively by intermittent suction and collected on ice in 30 -min periods. After an initial basic aspiration period of $20 \mathrm{~min}$, gall bladder contraction was promoted by intravenous injection of cholecystokinin (l clinical $\mathrm{U} / \mathrm{kg}$ body wt). The sampling period then lasted for $60 \mathrm{~min}(90 \mathrm{~min}$ in I.J. who was cholecystectomized). The amount of bile obtained varied from 82 to $410 \mathrm{ml}$.

Isolation and analysis of bile acids. Aliquots (10-30\%) of the bile portions were hydrolyzed in alkali, extracted, methylated, and subjected to preparative thin-layer chromatography. The different chromatographic zones were visualized by exposure to iodine vapor (22). The radioactivity in aliquots of the material eluted from the different zones of the chromatoplate was measured with an Intertechnique SL 30 liquid scintillation spectrometer, using Luma gel (LUMAC, BV Netherlands) as scintillation fluid. Under the conditions employed, the counting efficiency was $71 \%$ for ${ }^{14} \mathrm{C}$ and $49 \%$ for ${ }^{3} \mathrm{H}$. The material in the chromatographic zone corresponding to methyl ester of chenodeoxycholic acid was rechromatographed in the same thin-layer chromatographic system as above, and the purity of the isolated material was ascertained by GLC of the trimethylsilyl ether derivative using an SE-30 column. The material in the chromatographic zone corresponding to cholic acid was diluted with 50-100 mg of unlabeled methyl ester of cholic acid and the mixture was recrystallized three times. The radioactivity in the purified methyl ester of chenodeoxycholic acid and in the recrystallized methyl ester of cholic acid was then measured as above. Under the conditions employed, no cor rections for quenching were found to be necessary.

\section{RESULTS}

Conversion of $\left[4-{ }^{14} \mathrm{C}\right] 7 \alpha$-hydroxy-4-cholesten-3-one and $\left[6 \beta-{ }^{3} \mathrm{H}\right] 7 \alpha, 26$-dihydroxy-4-cholesten-3-one into bile acids. After administration of the above mixture to the two control subjects (L.A. and P.L.I.), $\sim 17$ and $75 \%$, respectively, of the administered ${ }^{3} \mathrm{H}$ activity and $\sim 28$ and $73 \%$, respectively, of the administered ${ }^{14} \mathrm{C}$ activity was recovered in the ether extract of the hydrolyzed bile sample collected. The lower recovery of bile from patient L.A. may have been due to an unfavorable position of the Lagerlöf tube. The percentage of the ${ }^{3} \mathrm{H}$ activity in cholic acid and chenodeoxycholic acid recovered in the ether extract is given in Table I. In addition to cholic acid and chenodeoxycholic acid, radioactivity was found in other fractions, the identity of which was not investigated. After further purification of the chenodeoxycholic acid fraction and crystallization of the cholic acid fraction to constant specific radioactivity, the ratio between ${ }^{14} \mathrm{C}$ and ${ }^{3} \mathrm{H}$ was determined. This ratio was $\sim 1.5$ in the cholic acid fraction and $\sim 0.4$ in the chenodeoxycholic acid fraction from both control subjects (Table I).
After administration of the same mixture to the CTX-patient (I.J.), $\sim 73 \%$ of the administered ${ }^{3} \mathrm{H}$ activity and $\sim 9 \%$ of the administered ${ }^{14} \mathrm{C}$ activity was recovered in the ether extract of the hydrolyzed bile sample collected. After purification and crystallization as above, the ratio between ${ }^{14} \mathrm{C}$ and ${ }^{3} \mathrm{H}$ was found to be $\sim 0.03$ in the cholic acid fraction and $\sim 0.006$ in the chenodeoxycholic acid fraction (Table I). These findings indicate a much less efficient conversion of the non-26-hydroxylated precursor into the primary bile acids than of the 26-hydroxylated precursor.

Conversion of $\left[4-^{14} \mathrm{C}\right] 5 \beta$-cholestane-3 $\alpha, 7 \alpha$-diol and $\left[1,2{ }^{3} H\right] 5 \beta$-cholestane- $3 \alpha, 7 \alpha, 26$-triol into cholic acid and chenodeoxycholic acid. After administration of the above mixture to the control subject, $\sim 70 \%$ of the ${ }^{3} \mathrm{H}$ activity and $\sim 42 \%$ of the ${ }^{14} \mathrm{C}$ activity was recovered in the ether extract of the hydrolyzed bile sample collected. The percentage of the ${ }^{3} \mathrm{H}$ activity in the ether extract recovered in cholic acid and chenodeoxycholic acid is given in Table $\mathbf{I}$. After purification and crystallization, the ratio between ${ }^{14} \mathrm{C}$ and ${ }^{3} \mathrm{H}$ was found to be $\sim 0.7$ in the cholic acid fraction and $\sim 0.10$ in the chenodeoxycholic acid fraction (Table I).

After administration of the same mixture to the CTX-patient (A.F.), $\sim 67 \%$ of the ${ }^{3} \mathrm{H}$ activity and $\sim 19 \%$ of the ${ }^{14} \mathrm{C}$ activity was found in the ether extract of the hydrolyzed bile acid sample collected. The fraction of the ${ }^{3} \mathrm{H}$ activity in the ether extract recovered in cholic acid and chenodeoxycholic acid is given in Table I. After purification and crystallization, the ratio between ${ }^{14} \mathrm{C}$ and ${ }^{3} \mathrm{H}$ was found to be $\sim 0.06$ in the cholic acid fraction and $\sim 0.004$ in the chenodeoxycholic acid fraction (Table I). Again, these findings indicate a much less efficient conversion of the non26-hydroxylated precursor.

The essential results of the in vivo experiments are also summarized in Fig. 1.

\section{DISCUSSION}

In previous in vitro studies we have presented evidence that the metabolic defect in CTX most probably is a lack of hepatic mitochondrial $\mathrm{C}_{27}$-steroid 26-hydroxylase $(6,7,21)$. If the 26 -hydroxylase is important in the normal biosynthesis of bile acids and this enzyme is defective in CTX, one would expect 26 -hydroxylated precursors to be rapidly converted into primary bile acids in patients with CTX as well as in control subjects. In the present in vivo study this was also found to be the case. Thus, the conversion of ${ }^{3} \mathrm{H}$-labeled $26-$ hydroxylated precursors into cholic acid + chenodeoxycholic acid was efficient in the CTX-patients as well as in the control subjects. In particular, the recovery in bile as chenodeoxycholic acid of the ${ }^{3} \mathrm{H}$ labeled 26-hydroxylated precursors was about the 

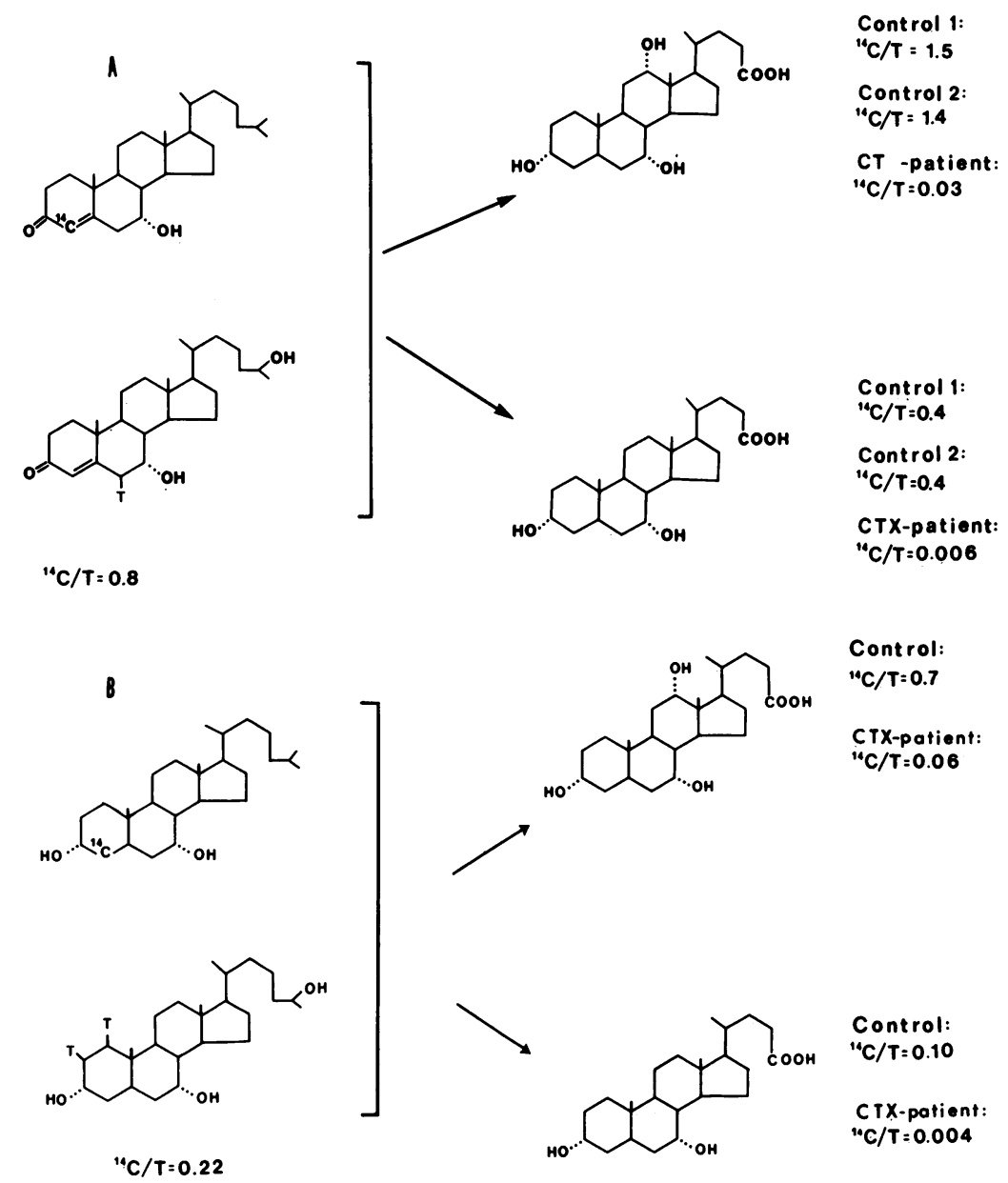

Figure 1 Results of the in vivo investigations with the double-labeled steroids. For details see Results.

same in the CTX patients as in the controls. These results are at variance with those of Salen et al. (11, 12), who reported that the in vivo conversion of several 26-hydroxylated intermediates into primary bile acids was delayed by $\sim 24 \mathrm{~h}$ in CTX patients compared with control subjects. Our data showed, however, that the ratio between ${ }^{3} \mathrm{H}$-activity in chenodeoxycholic and cholic acid was higher in the patients with CTX than in the controls (Table I). The explanation may be that in the biosynthesis of chenodeoxycholic acid in patients with CXT there is almost no dilution of the exogenously administered 26-hydroxylated precursors with endogenous precursor. In the biosynthesis of cholic acid, on the other hand, there will be a competition for the $12 \alpha$-hydroxylase because of increased amounts of endogenous substrates (6). Due to this competition, more of the 26-hydroxylated precursor may be channeled into the pathway leading to chenodeoxycholic acid.
If there is a block in the 26-hydroxylase pathway, $5 \beta$-cholestane- $3 \alpha, 7 \alpha$-diol and $7 \alpha$-hydroxy-4-cholesten-3-one can be expected to be converted into the primary bile acids considerably less efficiently than the corresponding 26-hydroxylated steroids. This was also found to be the case. Under the conditions employed, the conversion of the non-26-hydroxylated precursors in the CTX patients was reduced with a factor of 10 and 40, respectively, in the biosynthesis of cholic acid and 20 and 60 , respectively, in the biosynthesis of chenodeoxycholic acid.

In the normal liver there is a very rapid conversion of an administered precursor into bile acids, and it has been shown in bile fistula patients that the conversion is essentially complete after only one passage through the liver (23-25). In view of this, the ratio between ${ }^{14} \mathrm{C}$ - and ${ }^{3} \mathrm{H}$-activity (from the non-26-hydroxylated and the 26-hydroxylated precursor respectively) recovered in cholic acid and chenodeoxycholic acid 
formed in the control subjects is not likely to be changed with time. In the CTX-patients, however, there is probably a primary conversion of $\mathrm{C}^{14}$-labeled $5 \beta$-cholestane- $3 \alpha, 7 \alpha$-diol and $7 \alpha$-hydroxy-4-cholesten-3-one into the 25-hydroxylated pentols and tetrols, which are then slowly converted into cholic acid and possibly, to a small extent, also into chenodeoxycholic acid. Thus, the ratio between ${ }^{14} \mathrm{C}$ and ${ }^{3} \mathrm{H}$ in the primary bile acids in the CTX-patients may increase with time. In view of this, even more drastic differences between the CTX-patients and the control patients could have been obtained if the bile samples had been taken earlier after the administration, and less drastic differences could have been obtained if the samples had been taken later after the administration. Conclusions can thus be drawn from a single ratio determination only if marked differences are obtained. In the present experiments marked differences were in fact observed in the bile collected at a time interval of 14 $\mathrm{h}$ after the infusion. By that time all intermediates would normally be converted into bile acids and excreted in the bile (23-24) and the marked reduction in the ${ }^{14} \mathrm{C} /{ }^{3} \mathrm{H}$ ratio observed in the $\mathrm{CTX}$ patients as compared with the controls, must reflect a defective conversion of the ${ }^{14} \mathrm{C}$-labeled, non-26-hydroxylated precursors.

Introduction of a 26-hydroxyl group in $7 \alpha$-hydroxy4-cholesten-3-one and $5 \beta$-cholestane- $3 \alpha, 7 \alpha$-diol was found to increase the conversion into chenodeoxycholic acid in the control subjects with a factor of $\sim 2$ (the ${ }^{14} \mathrm{C} /{ }^{3} \mathrm{H}$ ratio was reduced by a factor of 2 ). This is in accordance with the previous finding that these 26-hydroxylated steroids are efficient precursors to chenodeoxycholic acid in vivo $(1,4,25)$. In the biosynthesis of cholic acid, however, the presence of a 26hydroxyl group reduced the biosynthesis with a factor of $\sim 50$ and $75 \%$, respectively, indicating that the $12 \alpha$ hydroxyl group is introduced more easily before the 26-hydroxyl group. Both these experiments are in accord with previous concepts with respect to the major pathway in the biosynthesis of cholic acid and chenodeoxycholic acid $(1,2)$.

The distribution of ${ }^{14} \mathrm{C}$-activity from $5 \beta$-cholestane$3 \alpha, 7 \alpha$-diol into cholic acid in the control subject was higher than could be expected, and the corresponding distribution into chenodeoxycholic acid was lower. According to current concepts $5 \beta$-cholestane- $3 \alpha, 7 \alpha$ diol should preferably be converted into chenodeoxycholic acid. On the other hand, individual variations may occur in the present type of in vivo experiments, and the findings obtained do not affect the general conclusions from the experiment.

In the present experiments, more marked differences were found with $7 \alpha$-hydroxy-4-cholesten-3-one and $7 \alpha, 26$-dihydroxy-4-cholesten-3-one than with $5 \beta$ - cholestane- $3 \alpha, 7 \alpha$-diol and $5 \beta$-cholestane- $3 \alpha, 7 \alpha, 26$-triol. It should be pointed out that different CTX-patients with different liver pathology were studied in the two sets of experiments, and thus individual variations may occur. In any case both sets of studies give rise to the same general conclusion.

There are several pitfalls in studies in vivo with labeled precursors. Some of the difficulties can be reduced with the present experimental approach, using two different precursors (with different labels) that reach the liver simultaneously. With the technique used, the errors and inconveniences related to estimation of absolute rates of synthesis could be avoided. The present results are in accordance with the contention that the basic metabolic defect in CTX is a lack of the 26-hydroxylase. When taken together with the in vitro data $(6,7)$ and other in vivo data $(4,23$, 26 ), the present work also gives strong support for the concept that the 26 -hydroxylase pathway is most important in the normal synthesis of bile acids.

\section{ACKNOWLEDGEMENTS}

The skillful technical assistance of Miss Anita Lövgren, Mrs. Kirsti Haug, and Mr. Manfred Held is gratefully acknowledged.

This work was supported by the Swedish Medical Research Council (project 03X-3141) and by the Norwegian Council for Science and the Humanities.

\section{REFERENCES}

1. Danielsson, H., and J. Sjövall. 1975. Bile acid metabolism. Annu. Rev. Biochem. 44: 233-253.

2. Björkhem, I., and H. Danielsson. 1976. In Progress in Liver Diseases. H. Popper and F. Schaffner, editors. Grune \& Stratton, Inc., New York. 215-231.

3. Björkhem, I., J. Gustafsson, G. Johansson, and B. Persson. 1975. Biosynthesis of bile acids in man. J. Clin. Invest. 55: 478-486.

4. Swell, L., J. Gustafsson, C. C. Schwartz, L. G. Halloran, H. Danielsson, and Z. R. Vlahcevic. 1980. An in vivo evaluation of the quantitative significance of several potential pathways to cholic and chenodeoxycholic acid from cholesterol in man. J. Lipid Res. 21: 455-466.

5. Björkhem, I., and J. Gustafsson. 1973. $\omega$-Hydroxylation of the steroid side-chain in biosynthesis of bile acids. Eur. J. Biochem. 36: 201-212.

6. Björkhem, I., H. Oftebro, S. Skrede, and J. I. Pedersen. 1981. Assay of intermediates in bile acid biosynthesis using isotope dilution-mass spectrometry: hepatic levels in the normal state and in cerebrotendinous xanthomatosis. J. Lipid Res. 22: 191-200.

7. Oftebro, H., I. Björkhem, S. Skrede, A. Schreiner, and J. I. Pedersen. 1980. Cerebrotendinous xanthomatosis: a defect in mitochondrial 26-hydroxylation required for normal biosynthesis of cholic acid. J. Clin. Invest. 65: 1418-1430.

8. Salen, G., S. Shefer, T. Setoguchi, and E. H. Mosbach. 1975. Bile alcohol metabolism in man. Conversion of $5 \beta$ cholestane-3 $\alpha, 7 \alpha, 12 \alpha, 25$-tetrol to cholic acid. J. Clin. Invest. 56: 226-231. 
9. Shefer, S., F. W. Cheng, B. Dayal, S. Hauser, G. S. Tint, G. Salen, and E. H. Mosbach. 1976. A 25-hydroxylation pathway of cholic acid biosynthesis in man and rat. $J$. Clin. Invest. 57: 897-903.

10. Setoguchi, T., G. Salen, G. S. Tint, and E. H. Mosbach. 1974. A biochemical abnormality in cerebrotendinous xanthomatosis. J. Clin. Invest. 53: 1393-1401.

11. Salen, G., S. Shefer, F. W. Cheng, B. Dayal, A. K. Batta, and G. S. Tint. 1979. Cholic acid biosynthesis. The enzymatic defect in cerebrotendinous xanthomatosis. $J$. Clin. Invest. 63: 38-44.

12. Salen, G., S. Shefer, E. H. Mosbach, S. Hauser, B. I. Cohen, and G. Nicolau. 1979. Metabolism of potential precursors of chenodeoxycholic acid in cerebrotendinous xanthomatosis (CTX). J. Lipid Res. 20: 22-30.

13. Orme-Johnson, W. H., and H. Beinert. 1969. Reductive titrations of iron-sulfur proteins containing two to four iron atoms. J. Biol. Chem. 244: 6143-6148.

14. Pedersen, J. I., and H. K. Godager. 1978. Purification of NADPH-ferredoxin reductase from rat liver mitochondria. Biochim. Biophys. Acta. 525: 28-36.

15. Oftebro, H., K. Saarem, I. Björ!nem, and J. I. Pedersen. 1981. Side chain hydroxylation of $\mathrm{C}_{27}$-steroids and vitamin $D_{3}$ by a cytochrome $P-450$ enzyme system isolated from human liver mitochondria. J. Lipid Res. 22: 12541264.

16. Björkhem, I. 1969. Stereochemistry of the enzymatic conversion of a $\Delta^{4}$-3-oxosteroid into a 3-oxo-5 $\beta$-steroid. Eur. J. Biochem. 7: 413-417.

17. Björkhem, I., H. Danielsson, and K. Einarsson. 1967. On the conversion of cholesterol to $5 \beta$-cholestane- $3 \alpha, 7 \alpha$-diol in guinea pig liver homogenates. Eur. J. Biochem. 2: 294-302.

18. Björkhem, I. 1969. On the mechanism of the enzymatic conversion of cholest-5-ene- $3 \beta, 7 \alpha$-diol into $7 \alpha$-hydroxycholest-4-en-3-one. Eur. J. Biochem. 8: 337-344.

19. Taniguchi, S., N. Hoshita, and K. Okuda. 1973. Enzymatic characteristics of $\mathrm{CO}$-sensitive 26 -hydroxylase system for $5 \beta$-cholestane- $3 \alpha, 7 \alpha, 12 \alpha$-triol in rat liver mitochondria and its intramitochondrial localization. Eur. J. Biochem. 40: 607-617.

20. Makita, M., and W. W. Wells. 1963. Quantitative analyses of fecal bile acids by gas-liquid chromatography. Anal. Biochem. 5: 523-530.

21. Oftebro, H., I. Björkhem, F. C. Stormer, and J. I. Pedersen. 1981. Cerebrotendinous xanthomatosis: defective liver mitochondrial hydroxylation of chenodeoxycholic acid precursors. J. Lipid Res. 22: 632-640.

22. Björkhem, I., and A. Lewenhaupt. 1979. Preferential utilization of newly synthesized cholesterol as substrate for bile acid biosynthesis. J. Biol. Chem. 255: 2925-2933.

23. Hanson, R. F. 1971. The formation and metabolism of $3 \alpha, 7 \alpha$-dihydroxy-5 $\beta$-cholestan-26-oic acid in man. $J$. Clin. Invest. 50: 2051-2055.

24. Hanson, R. F., P. D. Klein, and G. C. Williams. 1973. Bile acid formation in man: metabolism of $7 \alpha$-hydroxy4-cholesten-3-one in bile fistula patients. J. Lipid Res. 14: 50-53.

25. Vlahcevic, Z. R., C. C. Schwartz, J. Gustafsson, L. G. Halloran, H. Danielsson, and L. Swell. 1980. Biosynthesis of bile acids in man. Multiple pathways to cholic acid and chenodeoxycholic acid. J. Biol. Chem. 255: 29252933. 